\title{
Mefenoxam Sensitivity in Phytophthora cinnamomi Isolates
}

Jiahuai Hu and Chuanxue Hong, Hampton Roads Agricultural Research and Extension Center, Virginia Beach, VA 23455; Erik L. Stromberg, Department of Plant Pathology, Physiology and Weed Science, Virginia Polytechnic Institute and State University, Blacksburg 24061; and Gary W. Moorman, Department of Plant Pathology, The Pennsylvania State University, University Park 16802

\begin{abstract}
Hu, J., Hong, C., Stromberg, E. L., and Moorman, G. W. 2010. Mefenoxam sensitivity in Phytophthora cinnamomi isolates. Plant Dis. 94:39-44.

Phytophthora cinnamomi is a destructive root pathogen of numerous woody plant species in the ornamental plant nursery. Sixty-five isolates of $P$. cinnamomi were evaluated for mefenoxam sensitivity on $20 \%$ clarified V8 agar amended with mefenoxam at 0 or $100 \mu \mathrm{g} / \mathrm{ml}$. In the presence of mefenoxam at $100 \mu \mathrm{g} / \mathrm{ml}$, eight isolates were intermediately sensitive, with mycelium growth ranging between 11 and $18 \%$ of the nonamended control, and 57 isolates were highly sensitive, with little or no mycelium growth. Five intermediately sensitive and five sensitive isolates were chosen to characterize their responses to mefenoxam at $0,0.1,1,10$, and 100 $\mu \mathrm{g} / \mathrm{ml}$. For intermediately sensitive isolates, the mefenoxam concentration causing $50 \%$ inhibition of mycelium growth $\left(\mathrm{EC}_{50}\right.$ values) ranged between 0.03 and $0.08 \mu \mathrm{g} / \mathrm{ml} ; \mathrm{EC}_{50}$ values for sensitive isolates varied from 0.01 to $0.02 \mu \mathrm{g} / \mathrm{ml}$. Five intermediately sensitive and seven sensitive isolates were selected further to assess in vivo sensitivity to mefenoxam using Lupinus angustifolius 'Russell Hybrids'. Lupine seedlings were treated with distilled water or mefenoxam at label rate (Subdue MAXX, $1 \mathrm{fl}$. oz. of product per 100 gal.) and then, 2 days later, inoculated with a 5-mm-diameter mycelial plug of $P$. cinnamomi on each cotyledon. Mefenoxam-treated plants averaged more than $96 \%$ less disease than water-treated plants. Mefenoxam provided adequate protection of lupines from infection by all 12 isolates regardless of their in vitro levels of sensitivity to mefenoxam. The ability to develop mefenoxam resistance was assessed in $P$. cinnamomi isolates with different mefenoxam sensitivity by UV mutagenesis and adapting mycelium to increasing concentrations of mefenoxam. Both UV mutagenesis and mycelium adaptation generated isolates with reduced sensitivity to mefenoxam. These isolates, however, did not grow as quickly as their corresponding parent. This study suggests that $P$. cinnamomi populations from ornamental nurseries in Virginia are sensitive to mefenoxam.
\end{abstract}

Phytophthora cinnamomi Rands is one of the most destructive soilborne pathogens that attacks root systems of numerous plant species $(12,16,30)$. This widespread pathogen poses a great threat to the forestry as well as the fruit and ornamental industries worldwide. Infection by $P$. cinnamomi has resulted in the extinction of many native species of forest plants in Australia (16) and has the potential to cause significant ecological damage in North America. P. cinnamomi is responsible for significant losses of avocado, chestnut, and cranberry in the United States (12). In ornamental plant nurseries, $P$. cinnamomi attacks many shrubs and trees, including Rhododendron spp., Vaccinium spp., and Prunus spp.

Crown and root rots caused by $P$. cinnamomi are difficult to manage due to the pathogen's wide host range. $P$. cinnamomi

Corresponding author: J. Hu

E-mail: hjh@vt.edu

Accepted for publication 18 August 2009.

doi:10.1094/PDIS-94-1-0039

(C) 2010 The American Phytopathological Society produces a large number of chlamydospores that can persist in growth media for years (30). Symptomless plants and contaminated growth media harboring $P$. cinnamomi are the major means of spreading this pathogen from nursery to nursery and to the landscape $(2,24)$. Many plant species grown in U.S. nurseries are susceptible to $P$. cinnamomi. As a result, practical management strategies generally target conditions that inhibit infection and disease development. Although growers manage the disease by implementing this strategy through the use of clean stock plants, nursery hygiene, chlorination of irrigation water, and the use of pathogen-free potting mix, chemical control is still the most effective approach to manage Phytophthora root rot.

Systemic mefenoxam (Subdue MAXX; Syngenta, Greensboro, NC), an Renantiomer of metalaxyl introduced in 1977, is an important commercially available compound for control of diseases caused by Phytophthora spp. Mefenoxam has been used as a soil drench to control root rot and foliar diseases caused by Phytophthora spp. and Pythium spp. on numerous crops, including ornamentals $(8,12)$. Mefenoxam has strong inhibitory activities against both mycelial growth and sporulation. Its mode of action is selective inhibition of ribosomal RNA synthesis by affecting the activity of the RNA polymerases $(8,9)$. Due to its site specificity, the Fungicide Resistance Action Committee has rated mefenoxam as having high intrinsic risk of resistance development in target pathogens. Within 2 years of its introduction, several resistant strains of $P$. infestans emerged in potato fields across Europe. Since then, metalaxyl or mefenoxam resistance has been detected in other Phytophthora spp. $(13,18,19,27)$.

The first occurrence of mefenoxam resistance in U.S. plant nurseries was found in P. nicotianae and P. citricola isolates in southern California $(13,14)$. Afterward, mefenoxam resistance has been detected increasingly in several Phytophthora spp. recovered from nursery crops in other states $(14,18,19)$. For instance, more than $20 \%$ of $P$. nicotianae isolates and $80 \%$ of $P$. cryptogea isolates collected from greenhouses in North Carolina were resistant to mefenoxam at either 1 or 100 $\mu \mathrm{g} / \mathrm{ml}$ (19). Our previous studies found mefenoxam resistance in $26 \%$ of $P$. nicotianae isolates from ornamental nurseries in Virginia (18). In addition, several previous studies reported enhanced fitness and greater competitiveness of mefenoxam-resistant isolates of $P$. nicotianae and $P$. infestans $(18,22,28)$. Development of resistance to mefenoxam poses a threat to the continuous effectiveness of this compound in managing Phytophthora diseases.

Despite increasing reports of mefenoxam resistance within Phytophthora spp., few studies have been conducted to investigate the sensitivity level of $P$. cinnamomi populations to mefenoxam. Information on mefenoxam sensitivity and on the movement of resistant populations among nursery facilities is important to develop management strategies for Phytophthora root rot. The main objectives of this study were to (i) determine in vitro sensitivity level of $P$. cinnamomi isolates to mefenoxam, (ii) determine the mefenoxam concentration causing 50\% inhibition of mycelium growth ( $\mathrm{EC}_{50}$ values) of representative isolates, (iii) evaluate the efficacy of mefenoxam to protect lupines against infection by $P$. cinnamomi, and (iv) assess the risk of resistance development in $P$. cinnamomi. 


\section{MATERIALS AND METHODS}

Isolate origin and identity confirmation. Sixty-five isolates of $P$. cinnamomi were included in this study. Thirty-seven isolates were collected from ornamental plant nurseries in Virginia. These isolates were recovered from symptomatic Ilex spp. $(n=22)$, Myrica spp. $(n=6)$, Berberis spp. $(n=3)$, Kalmia spp. $(n=3)$, Heliamphora $\mathrm{sp} .(n=1)$, Rhododendron $\mathrm{sp} .(n=$ $1)$, and Viburnum sp. $(n=1)$. The remaining 28 isolates from West Virginia, North Carolina, South Carolina, Massachusetts, California, and China were also included in the population sample for comparison (Table 1). Most of these isolates were recovered after 2000. However, one isolate (23B2) was recovered from Persea americana in 1960, at least 10 years before metalaxyl was introduced into the U.S. market. The species identity of all isolates was verified using a single-strand conformation polymorphism (SSCP) analysis of the ribosomal DNA internal transcribed spacer 1 (23). All isolates tested yielded about a 300-bp amplicon and produced an SSCP banding pattern characteristic of Phytophthora cinnamomi on $8 \%$ polyacrylamide gels.
In vitro mefenoxam sensitivity. Two experiments were conducted to characterize in vitro sensitivity of $P$. cinnamomi isolates to mefenoxam. Experiment one used two concentrations (mefenoxam at 0 and $100 \mu \mathrm{g} / \mathrm{ml}$ ) to screen isolates. Thereafter, five intermediately sensitive isolates and five sensitive isolates were chosen from this initial experiment for use in experiment two. These isolates were assessed at five mefenoxam concentrations $(0,0.1$, 1,10 , and $100 \mu \mathrm{g} / \mathrm{ml}$ ) to determine their $\mathrm{EC}_{50}$ values.

Base medium was clarified $20 \%$ V8 (CV8) agar. Mefenoxam (Subdue MAXX; Syngenta) was diluted in sterile distilled water, then added to the autoclaved medium at $50^{\circ} \mathrm{C}$. Mycelium plugs $(5 \mathrm{~mm}$ in diameter) were cut from the margin of actively growing colonies of 3-day-old agar cultures. One mycelium plug was placed in the center of a 9-cm petri dish with mycelia in contact with the medium. Three replicate petri dishes were established for each isolate at each mefenoxam concentration. The dishes were then incubated at 23 to $25^{\circ} \mathrm{C}$ for 5 to 7 days in darkness. When colonies in nonamended control dishes had reached the edge of dishes, colony diameters were measured in two perpendicular directions for all treatments. The diameter of the mycelium plug was subtracted and the two measurements were averaged. The relative mycelium growth of an isolate on mefenoxam-amended media was calculated by dividing colony diameter in amended dishes by that in the nonamended control dishes, and expressed as percentage. Isolates were scored as sensitive (little or no growth), intermediately sensitive (growth less than $40 \%$ of control), and resistant (growth greater than $40 \%$ of control) (18).

In vivo tests with Lupinus angustifolius 'Russell Hybrids' seedlings. Five intermediately sensitive and seven sensitive isolates were further tested for in vivo mefenoxam-sensitivity in lupines. Lupine seedlings are highly susceptible to a number of Phytophthora spp., including $P$. cinnamomi (6), and have been used as a model system to test the efficacy of metalaxyl against $P$. cinnamomi (15). Seedlings treated with mefenoxam were later challenged with $P$. cinnamomi as described previously $(17,18)$. Lupine seed were induced to germinate by soaking them overnight in distilled water and then

Table 1. Host, year of isolation, geographic origin, and sensitivity to mefenoxam of Phytophthora cinnamomi isolates assessed in this study ${ }^{\mathrm{w}}$

\begin{tabular}{|c|c|c|c|c|c|}
\hline Host & Year of isolation & Geographic origin & No. of isolates & Sensitivity $^{\mathrm{x}}$ & $\operatorname{EC}_{50}(\mu \mathrm{g} / \mathrm{ml})^{y}$ \\
\hline Abies fraseri & 1986 & West Virginia & 2 & $3 \pm 0.2$ & ND \\
\hline A. fraseri & 1987 & West Virginia & 2 & $2 \pm 0.1$ & ND \\
\hline A. fraseri & 1989 & West Virginia & 1 & $3 \pm 0.1$ & ND \\
\hline A. fraseri & 2003 & West Virginia & 1 & $5 \pm 0.1$ & ND \\
\hline Berberis gladywensis & 2004 & Virginia & 1 & $1 \pm 0.1$ & ND \\
\hline B. thunbergii & 2002 & Virginia & 1 & $8 \pm 0.3$ & ND \\
\hline B. thunbergii & 2002 & Virginia & 1 & $2 \pm 0.2$ & ND \\
\hline Camellia japonica & 2001 & California & 1 & $0 \pm 0.0$ & 0.02 \\
\hline C. japonica & 2002 & South Carolina & 1 & $8 \pm 0.5$ & ND \\
\hline Castanea dentata & 1990 & Virginia & 1 & $6 \pm 0.3$ & ND \\
\hline C. dentata & 1990 & Virginia & 1 & $12 \pm 0.2$ & 0.02 \\
\hline Ginkgo biloba & 1997 & South Carolina & 1 & $16 \pm 0.1^{z}$ & 0.03 \\
\hline Heliamphora sp. & 1994 & Virginia & 1 & $1 \pm 0.0$ & ND \\
\hline Ilex glabra & 2004 & Virginia & 1 & $11 \pm 0.2^{z}$ & 0.04 \\
\hline I. glabra & 2004 & Virginia & 1 & $14 \pm 0.5^{z}$ & 0.03 \\
\hline I. glabra & 2004 & Virginia & 10 & $3 \pm 1.4$ & ND \\
\hline I. glabra & 2004 & Virginia & 10 & $0 \pm 0.4$ & 0.02 \\
\hline Kalmia latifolia & 2004 & Virginia & 3 & $2 \pm 0.4$ & ND \\
\hline Myrica cerifera & 2004 & Virginia & 4 & $0 \pm 0.0$ & ND \\
\hline M. pennsylvanica & 2004 & Virginia & 2 & $5 \pm 0.1$ & ND \\
\hline Persea americana & 2000 & California & 1 & $0 \pm 0.0$ & ND \\
\hline P. americana & 1960 & Puerto Rico & 1 & $18 \pm 0.2^{z}$ & 0.04 \\
\hline Pinus sp. & 2003 & West Virginia & 1 & $9 \pm 0.2$ & 0.01 \\
\hline Rhododendron sp. & 1999 & North Carolina & 1 & $1 \pm 0.1$ & ND \\
\hline Rhododendron sp. & 1989 & West Virginia & 1 & $2 \pm 0.3$ & ND \\
\hline Rhododendron sp. & 2003 & Virginia & 1 & $5 \pm 0.4$ & ND \\
\hline Taxus sp. & 1992 & Massachusetts & 1 & $0 \pm 0.0$ & 0.08 \\
\hline Vaccinium macrocarpon & 1987 & Massachusetts & 1 & $0 \pm 0.0$ & ND \\
\hline Viburnum sp. & 2003 & Virginia & 1 & $1 \pm 0.2$ & ND \\
\hline Forest soil & 2004 & China & 1 & $16 \pm 0.3^{z}$ & 0.07 \\
\hline$\ldots$ & 2003 & China & 1 & $11 \pm 0.1^{z}$ & ND \\
\hline$\ldots$ & $\ldots$ & $\ldots$ & 1 & $13 \pm 0.3^{z}$ & ND \\
\hline$\ldots$ & $\ldots$ & $\ldots$ & 7 & $4 \pm 0.8$ & ND \\
\hline
\end{tabular}

${ }^{\mathrm{w}}$ Symbol: ... indicates that details of these isolates are not known.

${ }^{x}$ Numbers are mean \pm three times standard deviation. An isolate's mycelium growth was measured on clarified V8 medium amended with mefenoxam at either 0 and $100 \mu \mathrm{g} / \mathrm{ml}$. Sensitivity was determined as percentage of mycelium growth with mefenoxam at $100 \mu \mathrm{g} / \mathrm{ml}$ compared with growth on control medium without the fungicide.

${ }^{\mathrm{y}} \mathrm{EC}_{50}$ value is the mefenoxam concentration causing $50 \%$ inhibition of mycelium growth. Assays were conducted twice by growing isolates on clarified $\mathrm{V} 8$ medium containing mefenoxam at $0,0.1,1,10$, and $100 \mu \mathrm{g} / \mathrm{ml}$. Each isolate was replicated six times; $\mathrm{ND}=$ not determined.

${ }^{\mathrm{z}}$ These isolates were classified as intermediately sensitive to mefenoxam. An isolate was classified as intermediately sensitive if mycelium growth at 100 $\mu \mathrm{g} / \mathrm{ml}$ was less than $40 \%$ of that on control medium. 
were placed on a moistened paper towel at $35^{\circ} \mathrm{C}$ for 2 to 3 days. Then, one germinating seed was transferred to grow in a plastic cup ( 15 by $10 \mathrm{~cm}$ ) containing vermiculite medium under white florescent light (10-h day and 14-h night) at room temperature. Plants were fertilized once a week with $50 \mathrm{ml}$ of general purpose fertilizer $\left(20 \% \mathrm{~N}, 20 \% \quad \mathrm{P}_{2} \mathrm{O}_{5}\right.$, and $20 \% \mathrm{~K}_{2} \mathrm{O}$; Scotts-Sierra Horticultural Products Co., Marysville, $\mathrm{OH}$ ) at $1 \mathrm{mg} / \mathrm{ml}$.

Two-week-old seedlings with fully expanded cotyledons were drenched with 25 $\mathrm{ml}$ of either distilled water or mefenoxam at label rate $(1 \mathrm{fl}$. oz. of Subdue MAXX per 100 gal.). Ten plants per treatment were used for each isolate. Each treatment was replicated four times within an experiment. All treated plants were arranged in a completely randomized design. Two days after mefenoxam treatment, both cotyledons of each seedling were inoculated with 5-mm mycelium plugs taken from the margin of 3-day-old cultures of each isolate. One plug was placed on the upper surface of each cotyledon. All inoculated plants were incubated in a moist chamber in the dark for $24 \mathrm{~h}$ to facilitate infection and then grown under florescent light at 23 to $25^{\circ} \mathrm{C}$. The number of symptomatic plants with brown lesions or dead plants was counted 5 days post inoculation.

Resistance induction. Three intermediately sensitive (15D8, 30E5, and 28E7) and two sensitive (28H5 and 28D8) isolates were selected to develop resistance by UV light mutagenesis and mycelium adaptation on medium with or without mefenoxam.

UV mutagenesis was conducted with a 10-W UV lamp at a wavelength of $254 \mathrm{~nm}$ by irradiating 3-day-old mycelium colonies grown on CV8 agar in open $90-\mathrm{mm}$ diameter petri dishes for $20 \mathrm{~min}$ at a distance of $50 \mathrm{~cm}$. Afterward, 5-mm mycelium discs were cut from margins of irradiated colonies and placed on CV8 agar medium containing mefenoxam at $5 \mu \mathrm{g} / \mathrm{ml}$. This concentration represented 100 times the mean $\mathrm{EC}_{50}$ values for intermediately sensitive isolates. Fifty petri dishes were established for each isolate. The dishes were incubated in the dark at $25^{\circ} \mathrm{C}$ for 2 weeks to allow for colony development. Mycelium plugs from each emerging colony were transferred to mefenoxamamended CV8 medium to confirm resistance at $5 \mu \mathrm{g} / \mathrm{ml}$. Mutant colonies were incubated for 1 week at $22^{\circ} \mathrm{C}$ before further determination of their $\mathrm{EC}_{50}$ values.

The mycelium adaptation protocol used in this study was similar to the procedure described previously (29). Mycelium plugs ( $5 \mathrm{~mm}$ in diameter) from actively growing margins were transferred to either CV8 agar amended with increasing concentration of mefenoxam or nonamended CV8 agar. Five dishes were replicated for each isolate. The initial concentration was twice the $\mathrm{EC}_{50}$ value of their corresponding parthe next cycle doubled that of the previous cycle if mycelium growth on mefenoxamamended agar was more than $50 \%$ of its corresponding parent isolate on nonamended control agar. After 1 week of incubation at $22^{\circ} \mathrm{C}$ in the dark, five mycelium plugs (5 $\mathrm{mm}$ in diameter) from the fastest growing sector of the colony were transferred to begin the next cycle. These weekly transfers were continued for 10 weeks. Colony diameters of mefenoxamadapted isolates and of parent isolates were recorded at the end of each transfer cycle. After the final transfer, the parent isolates and adapted isolates were assessed for $\mathrm{EC}_{50}$ values and differences in mycelium growth on nonamended CV8 agar.

Experiment design and data analysis. The mycelial adaptation and UV mutagenesis experiments were conducted once and all other experiments described above were conducted twice on different dates. Treatments within each repeating experiment were arranged in a completely randomized design. Data from two experiments were pooled together according to homogeneity of variance. $\mathrm{EC}_{50}$ values for each isolate were calculated by fitting linear regression lines of probittransformed percentage against the $\log _{10}$ of the mefenoxam concentration (PROC PROBIT of SAS, release 9.1; SAS Institute, Cary, NC). A Mann-Whitney $U$ test (31) was performed to determine differences in mortality of lupine seedlings between mefenoxam treatment and the watertreated control for each isolate. Analysis of variance and Fisher's protected least sigent isolates. Mefenoxam concentrations for

nificant difference were performed with PROC GLM (SAS Institute) to determine differences in disease control between intermediately sensitive and sensitive isolates.

\section{RESULTS}

In vitro mefenoxam sensitivity. The distribution of mefenoxam sensitivity among 65 isolates grouped by host is shown in Table 1. All isolates of P. cinnamomi were sensitive to mefenoxam at 100 $\mu \mathrm{g} / \mathrm{ml}$. Mycelium growth of all 65 isolates on CV8 agar amended with mefenoxam at $100 \mu \mathrm{g} / \mathrm{ml}$ was significantly inhibited compared with that on nonamended control CV8 medium. The inhibition effect of mefenoxam at $100 \mu \mathrm{g} / \mathrm{ml}$ on mycelium growth ranged from 82 to $100 \%$ of that on nonamended CV8 agar control. In all, 14 isolates had no mycelium growth in the presence of mefenoxam at $100 \mu \mathrm{g} / \mathrm{ml}$, but 8 intermediately sensitive isolates had mycelium growth ranging from 11 to $18 \%$ compared with that on the nonamended CV8 agar control (Table 1). There were more variations in mefenoxam sensitivity among isolates collected from different host species than from the same host. No significant correlations were observed between mefenoxam sensitivity and host species, geographic locations, or year of isolation.

Mycelium growth of intermediately sensitive isolates was consistently less inhibited by mefenoxam at all concentrations up to $100 \mu \mathrm{g} / \mathrm{ml}$ than that of sensitive isolates (Fig. 1). $\mathrm{EC}_{50}$ values of mefenoxam for intermediately sensitive isolates ranged from 0.03 to $0.08 \mu \mathrm{g} / \mathrm{ml}$ and $\mathrm{EC}_{50}$ values

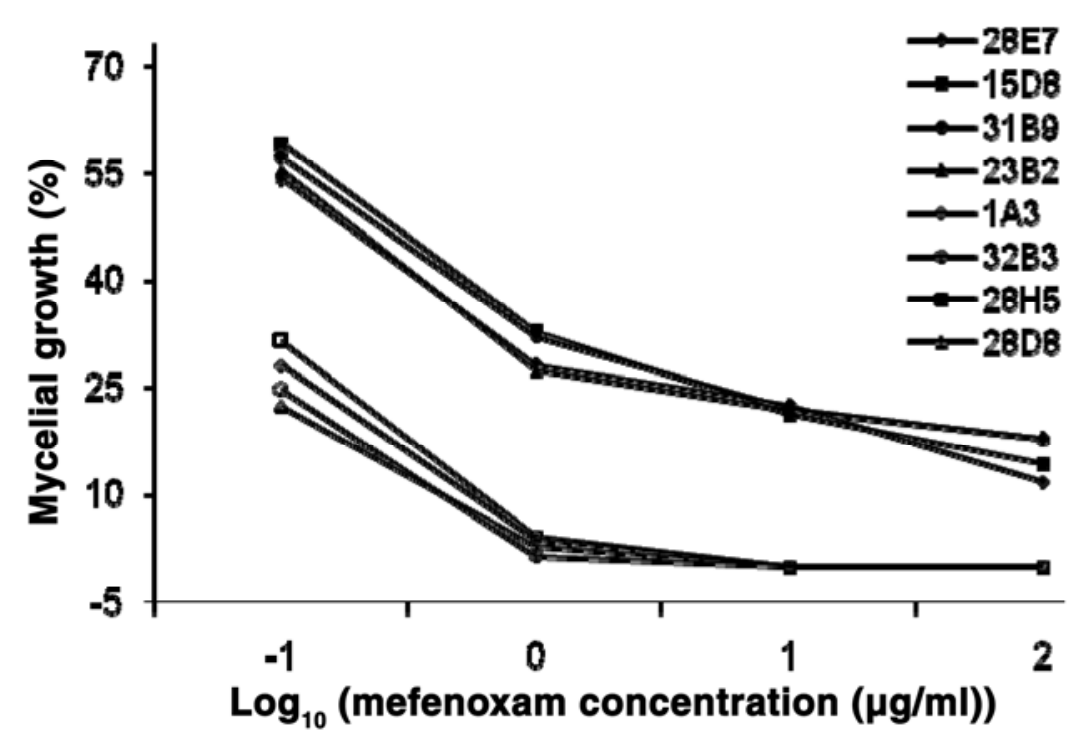

Fig. 1. Dose-response curves for mycelium growth on clarified V8 agar of four intermediately sensitive isolates and four sensitive isolates of Phytophthora cinnamomi. Mycelium growth was expressed as percent growth on mefenoxam-amended medium compared with that of the control medium. Isolate 31B9 and 32B3 were recovered from Ilex glabra in a Virginia nursery (2004), 28E7 from Castanea dentata in Virginia (1990), 15D8 from Ginkgo biloba (1997) in South Carolina, 23B2 from Persea americana in Puerto Rico (1960), 1A3 from Camellia japonica in California (2000), 28H5 from a Taxus sp. in Massachusetts (1992), and 28D8 from a Pinus sp. in West Virginia (2003). Each number is a mean value of six replicates from two experiments. 
for sensitive isolates varied from 0.01 to $0.02 \mu \mathrm{g} / \mathrm{ml}$ (Table 1).

In vivo tests with Lupinus angustifolius 'Russell Hybrids' seedlings. Cotyledons of water-treated lupine seedlings and seedlings inoculated with $P$. cinnamomi developed dark-brown lesions at inoculation sites; lesions quickly expanded to cover entire leaf surface and infected plants collapsed within a week. Mefenoxam-treated plants that were inoculated with sensitive isolates had no visible

symptoms. Mefenoxam-treated plants that were inoculated with intermediately sensitive isolates had symptoms similar to those observed on water-treated plants but lesions were often confined at the inoculation sites and most of the plants were not attacked by $P$. cinnamomi. Mefenoxam provided lupine good protection against infection by $P$. cinnamomi isolates, regardless of their in vitro sensitivity levels (Table 2). No significant difference in the ability to infect water-treated lupine plants

Table 2. Efficacy of mefenoxam in protecting Lupinus angustifolius 'Russell Hybrids' seedlings from infection by intermediately sensitive and sensitive isolates of Phytophthora cinnamomi

\begin{tabular}{lccl}
\hline & \multicolumn{2}{c}{ No. of diseased plants } & \\
\cline { 2 - 3 } Variable $^{\mathbf{w}}$ & Water & Mefenoxam $^{\mathbf{x}}$ & $\boldsymbol{P}^{\mathbf{y}}$ \\
\hline Isolate & & & \\
Intermediately sensitive & & & \\
30E5 & 9.7 & 0.3 & $<0.01$ \\
15D8 & 10.0 & 0.5 & $<0.01$ \\
28E7 & 9.2 & 0.5 & $<0.01$ \\
23B2 & 10.0 & 0.7 & $<0.01$ \\
31B9 & 10.0 & 0.6 & $<0.01$ \\
Sensitive & & & $<0.01$ \\
28D8 & 9.5 & 0.7 & $<0.01$ \\
31H2 & 9.8 & 0.4 & $<0.01$ \\
31H8 & 10.0 & 0.0 & $<0.01$ \\
28H5 & 9.3 & 0.7 & $<0.01$ \\
32D3 & 10.0 & 0.0 & $<0.01$ \\
32B3 & 9.5 & 0.0 & $<0.01$ \\
32C3 & 10.0 & 0.0 & $\ldots$ \\
Mean & & & $\ldots$ \\
Intermediately sensitive & 9.8 & 0.5 & $\ldots$ \\
Sensitive & 9.7 & 0.2 & \\
$P$ & 0.866 & $0.008^{* *}$ & \\
\hline
\end{tabular}

${ }^{w}$ Number of infected lupine with dark-brown lesions or dead plants. Each treatment was replicated four times per isolate. Seedlings were drenched with $25 \mathrm{ml}$ of either distilled water or mefenoxam at label rate (1 fl. oz. product/100 gal.).

$x$ An isolate was determined to be sensitive (little or no mycelial growth on clarified V8 agar medium amended with mefenoxam at $100 \mu \mathrm{g} / \mathrm{ml}$ ), intermediately sensitive (growth less than $40 \%$ of control), or resistant (growth greater than $40 \%$ of control).

${ }^{y}$ The Mann-Whitney $U$ test (1) was performed to determine the differences in mortality of lupine seedlings between mefenoxam treatment and water-treated control for each isolate.

${ }^{\mathrm{z}}$ One-way analysis of variance was performed to compare differences in mortality between two groups of isolates. Mean in each group is average of either six intermediately sensitive isolates or six sensitive isolates; $* *$ denotes significant difference at $P=0.01$.

Table 3. Development of resistance in Phytophthora cinnamomi isolates by mycelium adaptation on medium with or without mefenoxam and UV irradiation

\begin{tabular}{lccc}
\hline & \multicolumn{3}{c}{ Resistance factor $^{\mathbf{w}}$} \\
\cline { 2 - 3 } Isolate $^{\mathbf{y}}$ & \multicolumn{3}{c}{ Transfer 10 $^{\mathbf{x}}$} \\
\cline { 2 - 3 } & Nonamended & Mefenoxam-amended & UV mutagenesis \\
\hline Intermediately sensitive & 1.0 & 4.9 & 1.3 \\
15D8 & 1.0 & 1.2 & 1.6 \\
30E5 & 1.0 & 1.0 & NA \\
28E7 & & & \\
Sensitive & 1.0 & 2.3 & 2.1 \\
28H5 & 1.0 & 7.3 & NA \\
28D8 & & & \\
\hline
\end{tabular}

${ }^{\mathrm{w}}$ Resistance factor was determined by dividing the mefenoxam concentration causing $50 \%$ inhibition of mycelium growth $\left(\mathrm{EC}_{50}\right.$ value) for mutants by $\mathrm{EC}_{50}$ values for their corresponding parent isolates. $\mathrm{EC}_{50}$ assays were conducted twice by growing isolates on clarified V8 (CV8) medium containing mefenoxam at $0,0.1,1,10$, and $100 \mu \mathrm{g} / \mathrm{ml}$. Each isolate was replicated six times.

${ }^{x}$ Tenth transfer of the isolate weekly grown on mefenoxam-amended CV8 medium and nonamended control medium at $25^{\circ} \mathrm{C}$.

y Initial mefenoxam sensitivity: an isolate was determined to be sensitive (little or no mycelial growth on CV8 agar medium amended with mefenoxam at $100 \mu \mathrm{g} / \mathrm{ml}$ ), intermediately sensitive (growth less than $40 \%$ of control), or resistant (growth greater than $40 \%$ of control).

${ }^{\mathrm{z}}$ Mutation was induced by $20 \mathrm{~min}$ of UV irradiation of 3-day-old culture for each isolate; NA = not applied. was found between intermediately sensitive isolates and sensitive isolates but intermediately sensitive isolates had a significantly higher infection frequency than sensitive isolates $(P=0.01)$ in the presence of mefenoxam (Table 2).

Resistance induction. UV irradiation generated fewer mefenoxam-sensitive mutants, with $\mathrm{EC}_{50}$ values ranging from 1.3 to 2.1 times as much as their corresponding parent isolates. In the mycelium adaptation experiment, all five isolates did maintain their initial mefenoxamsensitivity levels after adaptation to CV8 medium without mefenoxam for 10 continuous weekly transfers (Table 3). Despite no change in the mefenoxam sensitivity level of isolate $28 \mathrm{E} 7$ after 10 weekly transfers on mefenoxam-amended medium, the other four adapted isolates were 1.2 to 7.3 times less sensitive compared with their corresponding parent isolates (Table 3). A gradual reduction in sensitivity to mefenoxam was observed for all four isolates. When grown on nonamended CV8 agar, mycelium growth of mefenoxam-adapted isolates was significantly less than that of their corresponding parent isolates, indicating mycelial growth impairment caused by resistance development (Table 4 ). No significant differences were observed between original parent isolates and their corresponding ones adapted on nonamended agar (Table 4), suggesting that sequential transfer on nonamended media had no impact on an isolate's mycelial growth rate.

\section{DISCUSSION}

This study demonstrates that the $P$. cinnamomi populations assessed were sensitive to mefenoxam in vivo, and this compound continues to provide effective control of this pathogen in nursery production. These results are quite different from our previous report of $26 \%$ of P. nicotianae isolates exhibiting mefenoxam resistance (18), although the majority of Virginian isolates of both species originated from the same nurseries. This discrepancy in mefenoxam sensitivity between the two species may have resulted from a number of factors. Specifically, the distinct nature of diseases caused by $P$. cinnamomi and $P$. nicotianae may lead to the pathogens' varying degrees of exposure to mefenoxam and, therefore, differential selection pressures for mefenoxam resistance. $P$. nicotianae is largely a foliar pathogen on herbaceous annual plant species. Its life cycle is repeated many times on different host species per growing season. Several applications of mefenoxam are required to deal with this high disease pressure. In contrast, soilborne $P$. cinnamomi mainly attacks root systems, and a longer incubation period is needed for the appearance of symptoms. As a result, fewer applications of mefenoxam are needed. Thus, selection pressure for mefenoxam resistance is much 
higher in $P$. nicotianae than in $P$. cinnamomi. In addition, even if the selection pressures in field conditions were high enough for resistance to mefenoxam to emerge in $P$. cinnamomi, mycelium growth impairment caused by mefenoxam resistance (Tables 3 and 4) could create a further barrier for their increase in the population and may be disadvantageous to their long-term survival in the absence of mefenoxam. The fact that mefenoxamresistant isolates of $P$. nicotianae had greater sporulation ability and competitiveness (18) also may have contributed to the rapid buildup of mefenoxam-resistant populations in the field. The fitness components such as sporulation ability, competitiveness, or virulence of intermediately sensitive isolates of $P$. cinnamomi should be further characterized along with the mefenoxam-resistant isolates of $P$. nicotianae.

In vivo mefenoxam-resistant isolates of $P$. cinnamomi were not found in this study. This result corroborated previous findings of no mefenoxam resistance detected in either $51 P$. cinnamomi isolates representing 23 genera of ornamental plants (11) or 42 isolates from 4 genera of ornamental crops (26). The magnitude of $\mathrm{EC}_{50}$ values ously reported values of $P$. cinnamomi isolates worldwide (7) and in North Carolina $(1,2)$. However, the discovery of a few intermediately sensitive isolates that could grow in the presence of mefenoxam at 100 $\mu \mathrm{g} / \mathrm{ml}$ should serve as an alert that mefenoxam sensitivity of $P$. cinnamomi is constantly evolving in ornamental nurserfenoxam is required for Phytophthora disease control. Furthermore, field application of mefenoxam could not control P. erythroseptica isolates with intermediate sensitivity (27). The biological significance of intermediately sensitive isolates identified in this study should be addressed in future work.

No association was observed between mefenoxam sensitivity and host species. The majority of nursery isolates representing 11 genera of ornamental crops exhibin this study was consistent with previies where at least three application of me-

ited little or no difference in their sensitivity to mefenoxam (Table 1). This result may imply that all nursery isolates used in this study belong to a single or few closely related clonages derived from a parental genotype. Previous molecular studies involving population structures of $P$. cinnamomi support the idea that this pathogen is a clonally spreading organism with three clonages worldwide (10). In addition, Schoenbaum (26) genotyped 42 nursery isolates of $P$. cinnamomi (4 isolates coming from this study) from five states but found that all isolates belong to a few asexually reproducing clonages, with a possible subdivision among hosts but not geographic locations. Meanwhile, another similar study with amplified fragment length polymorphism markers detected limited genetic variation among ornamental nursery populations of $P$. cinnamomi in South Carolina (11). Further detailed genetic characterization of isolates used in this study could yield better understanding of potential population subdivision based on host type or levels of mefenoxam sensitivity.

Although screening $P$. cinnamomi for sensitivity to mefenoxam on amended agar provides some assessment of sensitivity and although in vitro screening is a fast and inexpensive method to characterize fungicide sensitivity variation in plant pathogen populations $(2,7,18,28)$, results from in vitro screening may not accurately translate into actual sensitivity under in vivo conditions $(4,20,25)$. This inconsistency is likely caused by plant-fungicide interactions, mode of action, cultivar susceptibility, and differential impact of fungicide on stages of the pathogen life cycle (17).

No mefenoxam-resistant mutants were generated in experiments of UV mutagenesis and mycelium adaptation. However, isolates with reduced sensitivity were obtained and their mycelium growth appeared to be impaired compared with that of corresponding parent isolates (Tables 3 and 4). Multidrug efflux pumps of ATPbinding cassette transporters were responsible for intermediate mefenoxam-

Table 4. Mycelial growth rate in isolates of Phytophthora cinnamomi on clarified V8 medium after 10 transfers to mefenoxam-amended medium or nonamended medium

\begin{tabular}{lcccc}
\hline & \multicolumn{4}{c}{ Radial mycelium growth $(\mathbf{m m})^{\mathbf{w}}$} \\
\cline { 2 - 4 } Isolate & Original parent isolate & \multicolumn{2}{c}{ Transfer 10 } \\
\cline { 2 - 4 } & Nonamended & Mefenoxam-amended $^{\mathbf{x}}$ & LSD $^{\mathbf{z}}$ \\
\hline 15D8 & $75 \mathrm{a}$ & $75 \mathrm{a}$ & $63 \mathrm{~b}$ & 7 \\
28H5 & $76 \mathrm{a}$ & $76 \mathrm{a}$ & $64 \mathrm{~b}$ & 3 \\
28D8 & $63 \mathrm{a}$ & $64 \mathrm{a}$ & $48 \mathrm{~b}$ & 5 \\
30E5 & $81 \mathrm{a}$ & $82 \mathrm{a}$ & $74 \mathrm{~b}$ & 5 \\
\hline
\end{tabular}

${ }^{w}$ Mean of six replicates per isolate. Colony diameter was measured after 6-day incubation of culture at $25^{\circ} \mathrm{C}$ in the dark.

${ }^{x}$ Tenth transfer of an isolate grown on either mefenoxam-amended medium or nonamended medium.

${ }^{y}$ Mefenoxam concentration: $1 \mu \mathrm{g} / \mathrm{ml}$.

${ }^{\mathrm{z}}$ Means followed by the same letters in a row are not significantly different according to Fisher's protected least significant difference (LSD; $P=0.01$ ). sensitivity in $P$. infestans (21). It is possible that less sensitive isolates observed in this study were not genetic mutants but, rather, of physiological origin. The ability to develop a high level of resistance to mefenoxam has been reported in several Phytophthora spp., including $P$. capsici $(3,5,29)$, P. citricola (20), and P. infestans (29). However, the frequency of generating resistant mutants varied greatly among species of Phytophthora despite similar procedures adopted in these studies. It is possible that mefenoxam resistance mechanisms could be different or unrelated among Phytophthora spp. (18).

\section{ACKNOWLEDGMENTS}

This project was supported in part by the Virginia Agricultural Council. We thank Syngenta Crop Protection for supplying mefenoxam and S. Jeffers of Clemson University, Clemson, SC, H. Ho of State University of New York, New Paltz, and M. Gallegly of West Virginia University, Morgantown, for providing some of the isolates.

\section{LITERATURE CITED}

1. Benson, D. M. 1979. Efficacy and in vitro activity of two systemic acylalanines and ethazole for control of Phytophthora cinnamomi root rot of azalea. Phytopathology 69:174-178.

2. Benson, D. M., and Grand, L. F. 2000. Incidence of Phytophthora root rot of Fraser fir in North Carolina and sensitivity of isolates Phytophthora cinnamomi to metalaxyl. Plant Dis. 84:661-664.

3. Bower, L. A., and Coffey, M. D. 1985. Development of laboratory tolerance to phosphorus acid, and fosetyl-Al, and metalaxyl. Can. J. Plant Pathol. 7:1-6.

4. Bruck, R. I., Fry, W. E., and Apple, A. E. 1980. Effect of metalaxyl, an acylalanine fungicide, on developmental stages of Phytophthora infestans. Phytopathology 70:597-601.

5. Bruin, G. C. A., and Edgington, L. V. 1982 Induction of fungal resistance to metalaxyl by ultraviolet irradiation. Phytopathology 72:476480.

6. Chee, K. H., and Newhook, F. J. 1965. Improved methods for use in studies on $P h y$ tophthora cinnamomi Rands and other Phy tophthora species. N. Z. J. Agric. Res. 8:88-95.

7. Coffey, M. D., Klure, L. J., and Bower, L. A. 1984. Variability in sensitivity to metalaxyl of isolates of Phytophthora cinnamomi and Phytophthora citricola. Phytopathology 74:417422.

8. Cohen, Y., and Coffey, M. D. 1986. Systemic fungicides and the control of oomycetes Annu. Rev. Phytopathol. 24:311-338.

9. Davidse, L. C., Hofman, A. E., and Velthius, G. C. 1983. Specific interference of metalaxyl with endogenous RNA polymerase activity in isolate nuclei from Phytophthora megasperma f. sp medicagenisis. Exp. Mycol. 7:344-361.

10. Dobrowolski, M. P., Tommerup, I. C., Shearer, B. L., and O'Brien, P. A. 2003. Three clonal lineages of Phytophthora cinnamomi in Australia revealed by microsatellites. Phytopathology 93:695-704.

11. Duan, C.-H., Riley, M. B., and Jeffers, S. N. 2008. Characterization of Phytophthora cinnamomi populations from ornamental plants in South Carolina, USA. Arch. Phytopathol. Plant Prot. 41:14-30.

12. Erwin, D. C., and Ribeiro, O. K. 1996. Phytophthora Diseases Worldwide. American Phytopathological Society Press, St. Paul, MN.

13. Ferrin, D. M., and Kabashima, J. N. 1991. In vitro insensitivity to metalaxyl of isolates of Phytophthora citricola and P. parasitica from ornamental hosts in southern California. Plant 
Dis. 75:1041-1044.

14. Ferrin, D. M., and Rohde, R. G. 1992. In vivo expression of resistance to metalaxyl by a nursery isolate of Phytophthora parasitica from Catharanthus roseus. Plant Dis. 76:8284.

15. Geissler, A. E., and Katekar, G. F. 1983. Effect of fungicides on stages of the life cycle of Phytophthora cinnamomi. Pestic. Sci. 14:501-507.

16. Hardham, A. R. 2005. Phytophthora cinnamomi. Mol. Plant Pathol. 6:589-604.

17. $\mathrm{Hu}$, J. H., Hong, C. X., Stromberg, E. L., and Moorman, G. W. 2007. Effects of propamocarb hydrochloride on mycelial growth, sporulation, and infection by Phytophthora nicotianae isolates from Virginia nurseries. Plant Dis. 91:414-420.

18. Hu, J. H., Hong, C. X., Stromberg, E. L., and Moorman, G. W. 2008. Mefenoxam sensitivity and fitness analysis of Phytophthora nicotianae isolates from Virginia nurseries. Plant Pathol. 57:728-736.

19. Hwang, J., and Benson, D. M. 2005. Identification, mefenoxam sensitivity, and compatibility type of Phytophthora spp. attacking floriculture crops in North Carolina. Plant
Dis. 89:185-190.

20. Joseph, M. C., and Coffey, M. D. 1984. Development of laboratory resistance to metalaxyl in Phytophthora citricola. Phytopathology 74:1411-1414.

21. Judelson, H. S., and Senthil, G. 2006. Investigating the role of $\mathrm{ABC}$ transporters in multifungicide insensitivity in Phytophthora infestans. Mol. Plant Pathol. 7:17-29.

22. Kadish, D., and Cohen, Y. 1988. Fitness of Phytophthora infestans isolates from metalaxyl-sensitive and -resistant populations. Phytopathology 78:912-915.

23. Kong, P., Hong, C. X., Richardson, P. A., and Gallegly, M. E. 2003. Single-strandconformation polymorphism of ribosomal DNA for rapid species differentiation in genus Phytophthora. Fungal Genet. Biol. 39:238249.

24. Kong, P., X., H. C., and Richardson, P. A. 2003. Rapid detection of Phytophthora cinnamomi using PCR with primers derived from the Lpv putative storage protein genes. Plant Pathol. 53:681-693.

25. Moorman, G. W., and Kim, S. H. 2004. Species of Pythium from greenhouses in Pennsyl- vania exhibit resistance to propamocarb and mefenoxam. Plant Dis. 88:630-632.

26. Schoenbaum, E. A. 2008. Genotypic Characterization of Phytophthora cinnamomi from Ornamental Crops in North Carolina. North Carolina State University, Raleigh.

27. Taylor, R. J., Pasche, J. S., and Gudmestad, N. C. 2006. Biological significance of mefenoxam resistance in Phytophthora erythroseptica and its implications for the management of pink rot of potato. Plant Dis. 90:927 934.

28. Timmer, L. W., Graham, J. H., and Zitko, S. E. 1998. Metalaxyl-resistant isolates of Phytophthora nicotianae: occurrence, sensitivity, and competitive parasitic ability on citrus. Plant Dis. 82:254-261.

29. Young, D. H., Spiewak, S. L., and Slawecki, R. A. 2001. Laboratory studies to assess the risk of development of resistance to zoxamide. Pest Manage. Sci. 57:1081-1087.

30. Zentmyer, G. A. 1980. Phytophthora cinnamomi and the Diseases it Causes. The American Phytopathological Society, St Paul, MN.

31. Zuwaylif, F. H. 1979. General Applied Statistics. Addison-Wesley, Menlo Park, CA. 